
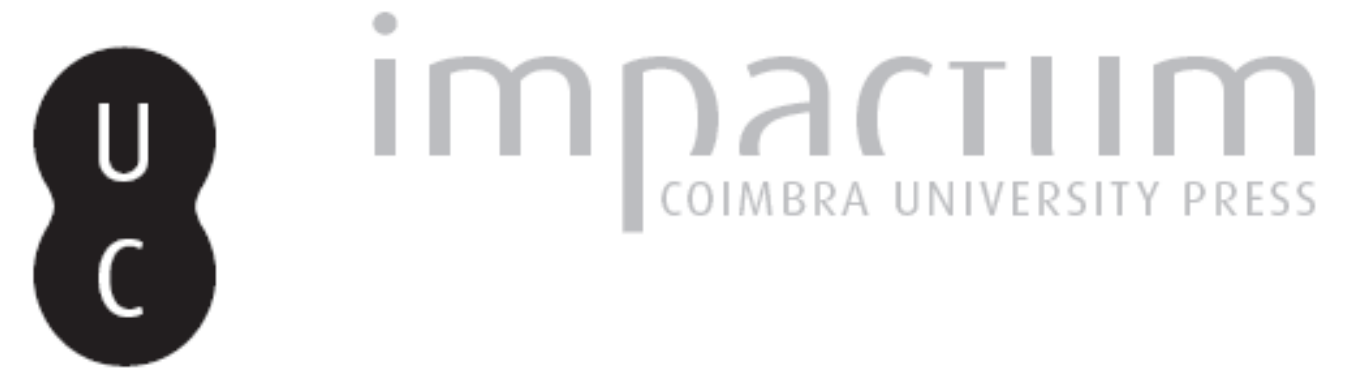

\title{
As Cartas de Soror Mariana: o epistolar como discurso da paixão
}

\section{Autor(es): $\quad$ Peixinho, Ana Teresa}

Publicado por: Imprensa da Universidade de Coimbra

URL persistente:

URI:http://hdl.handle.net/10316.2/35455

DOI:

DOI:http://dx.doi.org/10.14195/0870-4112_11_2

Accessed : $\quad$ 26-Apr-2023 10:36:53

A navegação consulta e descarregamento dos títulos inseridos nas Bibliotecas Digitais UC Digitalis, UC Pombalina e UC Impactum, pressupõem a aceitação plena e sem reservas dos Termos e Condições de Uso destas Bibliotecas Digitais, disponíveis em https://digitalis.uc.pt/pt-pt/termos.

Conforme exposto nos referidos Termos e Condições de Uso, o descarregamento de títulos de acesso restrito requer uma licença válida de autorização devendo o utilizador aceder ao(s) documento(s) a partir de um endereço de IP da instituição detentora da supramencionada licença.

Ao utilizador é apenas permitido o descarregamento para uso pessoal, pelo que o emprego do(s) título(s) descarregado(s) para outro fim, designadamente comercial, carece de autorização do respetivo autor ou editor da obra.

Na medida em que todas as obras da UC Digitalis se encontram protegidas pelo Código do Direito de Autor e Direitos Conexos e demais legislação aplicável, toda a cópia, parcial ou total, deste documento, nos casos em que é legalmente admitida, deverá conter ou fazer-se acompanhar por este aviso.

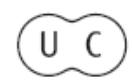




\section{ESTÉTICA E POLÍTICA}

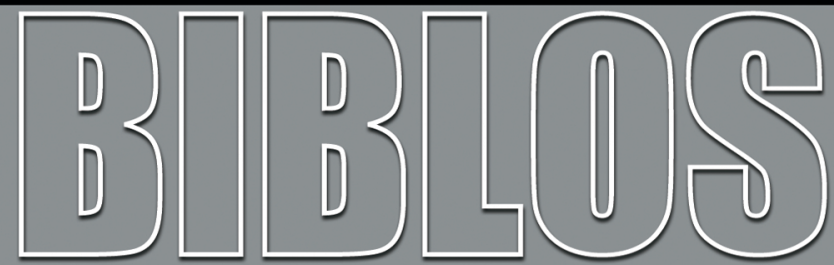

REVISTA DA FACULDADE DE LETRAS UNIVERSIDADE DE COIMBRA 
Biblos, n. s. XI (2013) 39-59

DOI: http://dx.doi.org/10.14195/0870-4112_11_2

Ana Teresa Peixinho

FLUC/CEIS2O

\section{AS CARTAS DE SOROR MARIANA: O EPISTOLAR COMO DISCURSO DA PAIXÃO}

Dois poderosos mitos fizeram-nos acreditar que o amor podia, devia sublimar-se em criação estética: o mito socrático (amar serve para criar uma multidão de belos e magníficos discursos) e o mito romântico (produzirei uma obra imortal escrevendo a minha paixão).

ROLAND BARTHES

\section{Resumo}

O sucesso da obra Lettres Portugaises, que extravasa o âmbito meramente nacional, prende-se sobretudo, na nossa opinião, com o caráter enigmático e com a aura de mistério que a envolve, decorrentes de motivos diversos, que foram já suficientemente identificados pela crítica.

Desde a publicação das cartas da religiosa portuguesa, no fim do século XVII, que a carta é entendida como medium apropriado e adequado à expressão espontânea da intimidade e da paixão. Contudo, sublinhe-se que, tal como sucede com outras criações literárias da época, a negligência e a impulsividade das cartas de Mariana são efeitos textuais, mais pensados e refletidos do que à primeira vista possa parecer. Embora haja uma corrente da crítica que defende a veracidade da história da Soror Mariana, baseada inclusive em pesquisa documental, entendemos relegar essa questão para segundo plano. Independentemente da existência empírica da figura e da veracidade ou não destas cartas, entendemos que, a partir do momento em que elas são coligidas, ordenadas e publicadas por um editor, elas adquirem uma dimensão orgânica que escapa à lógica de julgamento referencial.

No caso das Lettres Portugaises, é o ato de produção do discurso o elemento diegético fundamental, o que secundariza de certa forma o destinatário eleito. Será através do discurso que Mariana enceta um processo catártico de autoanálise, que lhe permitirá trilhar um processo de racionalização.

Palavras-chave: Epistolar, carta, paixão, discurso. 


\begin{abstract}
The success of the work Lettres Portugaises, going beyond the purely national context, is mainly due, in our opinion, to the enigmatic character and the aura of mystery that surrounds it, due to various reasons, which have been sufficiently identified by critics.

Since the publication of the letters of the Portuguese religious, in the late seventeenth century, that the letter is seen as the appropriate and suitable medium to the spontaneous expression of intimacy and passion. However, it should be noted that, as with other literary creations of time, neglect and impulsivity in the letters of Mariana are essentially textual effects. Although there is a current of criticism that defends the veracity of the story of Sister Mariana, even based on documentary research, in our opinion this is not the most important point. Regardless of the empirical existence of the figure and the truth of these letters, we understand that, from the moment they are collected, sorted and published by a publisher, they acquire an organic dimension that escapes the logic of referential judgment.

In the case of the Portuguese Lettres, it is the act of speech production the fundamental diegetic element, moving to the background the designated addressee. It is through speech that Mariana undertakes a cathartic process of self-analysis, which will allow her to follow a process of rationalization.
\end{abstract}

Keywords: Epistolary, letter, passion, speech. 


\section{Uma fórmula de sucesso}

O sucesso da obra Lettres Portugaises, que extravasa o âmbito meramente nacional, prende-se sobretudo, na nossa opinião, com o caráter enigmático e com a aura de mistério que a envolve, decorrentes de motivos diversos, que foram já suficientemente identificados pela crítica. Antes de mais, trata-se de um texto anónimo, cuja autoria nunca foi verdadeiramente atribuída, pesem embora as inúmeras investigações a que deu origem, pelo menos desde o século XIX. A coberto deste anonimato, muito se tem especulado sobre a identidade do autor ou da autora destas cartas: terá sido um homem a escrevê-las, usando a máscara da personagem Mariana? Ou são elas fruto da escrita de uma jovem freira portuguesa, cuja existência empírica foi atestada por alguns? Este debate arrasta-se desde que um erudito francês oitocentista, Jean-François Boissonade, identificou Mariana Alcoforado como a suposta autora das cartas de amor. Independentemente da resposta que, acreditamos, nunca passará de conjetura, esta questão tem fascinado a crítica e é um indiscutível fator de sedução.

Além deste aspeto, que inclusive ditou inúmeras leituras críticas sobre a feminilidade da escrita dos textos, há um outro tema que tem atraído alguns investigadores e não menos curiosos: trata-se da integração das Cartas no cânone da Literatura Portuguesa. É sabido que a obra foi originalmente publicada em língua francesa e que a primeira tradução para português data de 1819 e foi da responsabilidade de Filinto Elísio ${ }^{1}$. Também é sabido que, ao longo de mais de século e meio de existência, esta obra terá suscitado uma grande curiosidade por parte de críticos e de literatos franceses, por oposição ao aparente silenciamento a que foi votada em Portugal. A especialista Anna Klobucka adianta, como explicação para esta receção tardia, o ambiente de censura inquisitória, sublinhando que a única referência às Cartas portuguesas anterior ao século XIX foi feita pelo estrangeirado Cavaleiro de Oliveira (Klobucka, 2006: 13-14). A este respeito, remetemos para

${ }^{1}$ Como explica Anna Klobucka, "as primeiras traduções das cartas para o seu suposto idioma original foram igualmente produzidas por exilados portugueses, respetivamente, em 1819 por Filinto Elísio e em 1825 por José Maria de Sousa Botelho" (Klobucka, 2006: 14). Sobre as traduções desta obra para português veja-se Paradinha, 2006. 
a recente obra desta estudiosa, em que se aborda o fenómeno Alcoforado como um mito, no sentido barthesiano do termo. Um mito que se cria na centúria de oitocentos e é perpetuado por inúmeros intelectuais e escritores pelo século seguinte, e que é "um produto do revivalismo nacionalista dos séculos XIX e XX" (Klobucka, 2006: 21 e ss.). Como veremos, a questão da pertença desta obra à literatura nacional não será um fator que aprofundaremos aqui, nem é muito pertinente para a nossa abordagem, sendo que em todas as bibliotecas de todo o mundo a obra está catalogada como pertencendo à literatura portuguesa, conforme reconhece Linda Kauffman, crítica americana que perspetiva as Cartas através de um enfoque feminista (Kauffman, 1986: 92).

Um terceiro fator que, em nosso entender, ajudou a alimentar a permanência desta obra e a justificar o seu enorme sucesso que se prolonga pelos séculos XX e XXI, prende-se precisamente com a sua construção discursiva epistolar. E será precisamente este o ponto de que partiremos nesta abordagem: tentar perceber de que forma o modo discursivo epistolar é o modo de comunicação da paixão por excelência, por um lado; e, por outro, captar nesta matriz a origem de um debate muito sedutor entre ficção e realidade, aspeto que inclusive entusiasmou muitos alcoforadistas. Não esqueçamos, no entanto, que o êxito desta obra é muito anterior, remontando ao final do século XVII: as Lettres Portugaises tiveram uma ampla aceitação na Europa ocidental ${ }^{2}$ e "écrire à la portugaise" tornou-se uma fórmula codificada para um certo estilo epistolar amoroso, inclusive citada pela grande epistológrafa contemporânea Mme. de Sévigné. A repercussão das Cartas da freira portuguesa deve ser perspetivada, em nosso entender, não tanto em função do anonimato do autor ou da ambiguidade da origem, mas sobretudo em função da sua formulação modal e discursiva que não é de todo a alheia ao contexto histórico-cultural do século XVII, como veremos mais adiante.

\section{A epistolaridade e o discurso amoroso}

Num ensaio sobre as formas de escrita pessoal - «A Escrita de $\mathrm{Si}$ » -, Michel Foucault diz, a respeito da carta, o seguinte:

${ }^{2}$ Conforme regista Linda Kauffman, antes de 1740, a tradução inglesa das Cartas atingiu as dez edições (Kauffman, 1986: 95). 
Escrever é, pois, "mostrar-se”, dar-se a ver, fazer aparecer o rosto próprio junto ao outro. E deve-se entender por tal que a carta é simultaneamente um olhar que se volve para o destinatário (por meio da missiva que recebe, ele sente-se olhado) e uma maneira de o remetente se oferecer ao seu olhar pelo que de si mesmo lhe diz. De certo modo, a carta proporciona um face-a-face (Foucault, 1995:151).

Esta poderia ser uma definição do objeto carta, enquanto forma discursiva que possibilita a abertura do sujeito ao olhar e ao julgamento do outro e de si mesmo, por um lado, e, por outro, uma forma de escrita em que o tipo de relação que se estabelece tem um paralelo no modelo comunicativo da oralidade, no discurso vivo in praesentia da situação de troca oral.

Esta metáfora da carta como "conversa entre ausentes" não é recente e remonta a uma tradição ciceroniana que previa para a escrita da carta um certo tipo de estilo, negligente, informal e natural, cristalizado na fórmula latina da negligentia epistolarum, tópico que permaneceu durante séculos na teorização da carta como texto simples, informal e similar ao diálogo. A conversacionalização que invade a escrita epistolar foi retomada, como tópico incontornável, pelos manuais epistolares que começaram a ser publicados no século XVI e que perduraram até finais do século XIX, sempre com grande vitalidade e acompanhando as evoluções e as nuances das práticas epistolares.

A coloquialidade da carta - uma conversa por escrito - vem ao encontro de um outro tópico, indiretamente sugerido pelas palavras de Foucault supracitadas, que se prende com a espontaneidade inerente ao epistolar. Entende-se, desde muito cedo, a escrita da carta como uma escrita ao correr da pena, negligente, natural, impulsiva, como se entre a expressão do sujeito e a carta não houvesse nenhuma mediação. Postula-se quase o apagamento do discurso, ou, pelo menos, a ideia utópica de um discurso totalmente transparente que tivesse a capacidade de espelhar a alma do sujeito. A esta luz, percebe-se um pouco melhor a perspetiva do mito da feminilidade do epistolar, pressupondo-se que a mulher seria um ser mais propenso a produzir discursos ligeiros, delicados e naturais, porque detentora de uma instrução menos cuidada e de uma cultura mais frágil; como tal, em relação ao homem, a mulher seria estrutural e naturalmente vocacionada para o estilo epistolar. Não é decerto coincidência que seja uma mulher o grande arquétipo literá- 
rio do género: Mme. de Sévigné foi eleita, pelos epistológrafos do seu tempo e do século seguinte, como o modelo a seguir, por tudo o que o seu discurso possuía de natural e sincero, de espontâneo e sedutor, de sensível e intimista.

Esta "estética da negligência" fundada no final do século XVII, época em que se vai abandonando progressivamente a eloquência académica e o modelo epistolar oratório, para dar lugar a uma escrita mais mundana, tem raízes nos postulados de Cícero e também nos de Erasmo $^{3}$, referência incontornável da renovação epistolar empreendida pelo Humanismo. Esta evolução, operada entre o século XVI e o século XVII, conduziu a uma espécie de humanização da palavra: a escrita da carta passa a exprimir o "eu individual" e o "eu social", refletindo diretamente a alma de quem a enuncia ${ }^{4}$.

Uma leitura de Lettres Portugaises permite-nos precisamente constatar algumas destas marcas do epistolar. Massaud Moisés, reconhecido estudioso brasileiro, refere o seguinte a propósito das cartas da religiosa portuguesa:

Realmente digno de nota, por sua altitude e invulgaridade, o fato de conterem as cartas a sincera, franca e escaldante confissão duma mulher que se desnuda interiormente para o amante cínico, ingrato e ausente,

\footnotetext{
${ }^{3}$ No seu Libellus de Conscribendis Epistolis, Erasmo entendeu a dialética que a forma epistolar envolvia: simultaneamente uma forma literária, com os seus preceitos próprios, e efusão espontânea e natural da intimidade do escritor. Num manual recente sobre tipologia e construção textual, José Esteves Rei define a carta nos seguintes termos: "É uma conversa por escrito, dirigida a uma pessoa ausente - assim se define tradicionalmente a carta. (...) a sua atualidade mantém-se tal como as suas características: economia, personalização, substituto do diálogo." (Rei, 2000: 158).

${ }^{4}$ Ressalve-se que, durante o Renascimento e mesmo em épocas mais tardias, a carta foi também um género cultivado por filósofos, pensadores e homens de letras, como forma de construir raciocínios lógicos, encetar debates de ideias e apresentar argumentações. Trata-se, contudo, de outro tipo de epistolografia: se pensarmos em nomes como os de Voltaire, autor das célebres Lettres Philosophiques, de Diderot que escreveu entre 1749 e 1751 as Lettre sur les aveugles e Lettre sur les sourds et muets, de Rousseau, autor da Lettre à d'Alembert sur les spectacles datada de 1758, ou de John Locke que publicou em 1689 a Letter on Tolerance, perceberemos que o epistolar é o meio ideal para resgatar a agilidade do pensamento e do raciocínio "sans tomber dans les pesanteurs de «la» pensée." (Diaz, 1998: 33). A este respeito veja-se: Peixinho, 2011.
} 
com fúria de fêmea abandonada, sem qualquer rebuço ou pudor (Moisés, 2001: 90).

Sublinhamos a tripla adjetivação - "sincera, franca e escaldante" com que o académico carateriza o discurso da enunciadora destas cartas, Mariana. Na verdade, a carta de abertura, assumida como uma resposta a uma hipotética missiva enviada pelo amado, surge como um enunciado espontâneo e natural, através do qual a enunciadora acusa o amor ausente (destinatário epistolar) do sofrimento causado pelo abandono. O tom da carta é altamente hiperbólico, egocentrado e passional, como o atestam as tradicionais marcas linguísticas das interjeições, das exclamativas, das repetições anafóricas e das perguntas retóricas. A enunciação discursiva, para recorrer à tipologia de Benveniste, é centrada no eu e no $t u$, protagonistas da cena epistolar e da retórica passional.

Quer isto dizer que, logo na primeira missiva, se instaura um pacto comunicacional que possibilita ao leitor aceder a um conjunto de princípios importantes para descodificar o sentido da obra: i) trata-se de um conjunto de cartas mais vasto, das quais apenas acedemos a estas cinco; ii) trata-se de uma escrita íntima em que uma enunciadora feminina sofre os tormentos do fim de uma relação; iii) o discurso traz marcas claras de uma escrita espontânea, natural, pouco racionalizada, capaz de traduzir as flutuações emocionais da enunciadora; iv) a escrita instaura-se como um meio catártico pela qual a protagonista se tenta reconstruir como sujeito, após o trauma e a violência da rutura amorosa. Aliás, em diversos momentos, a própria Mariana confessa escrever mais para si própria do que para o seu destinatário. Este último ponto parece-nos de grande relevância para se perceber a importância do modo epistolar na construção do sujeito Mariana e a ele voltaremos mais adiante.

$\mathrm{Na}$ verdade, uma vez que a carta é um discurso escrito fundado na ausência do destinatário, como aliás o são todos os discursos escritos, esta relação com o modelo oral deve ser matizada e repensada, pois ao contrário do que sucede na interação oral, nesta situação não há copresença, sendo que a figura do destinatário só artificialmente, por meio de uma construção discursiva, consegue presentificar-se ${ }^{5}$. Fundando-se na

${ }^{5}$ Daí que Teresa Almeida diga que "se a carta deve ser a reprodução de uma hipotética conversa por haver, não o sendo na realidade, há que criar um meca- 
ausência ${ }^{6}$, a carta cria a ilusão da presença, inventa-se como discurso dialógico com um ser de papel. E esta ausência - fundamental para o ato de escrita e para a existência da própria carta - permite ao epistológrafo criar imagens de si, projetar identidades possíveis, conhecer-se e dialogar consigo mesmo, embora o seu horizonte primeiro seja a figura do destinatário a quem se dirige. Por isso, Brigitte Diaz, defendendo que a carta é um discurso que, mais do que estabelecer pontes ou "conversas" com o outro, se fecha sobre si mesmo, é da opinião que o discurso epistolar é uma atividade de resistência ao outro, em que a emergência do sujeito que se instaura na cenografia epistolar decorre precisamente da ausência do outro (Diaz, 2002: 59).

Os aspetos que acabamos de enunciar sobre as cartas de Mariana funcionam, na nossa opinião, como operadores do real, insinuando uma factualidade e uma espontaneidade mais adequadas a uma correspondência privada do que a uma criação literária, o que não deixa de ser um sintoma claro deste tipo de ficção da época. Contudo, sem querermos enveredar pela celeuma da existência ou não de uma Mariana Alcoforado e de um oficial francês, parece-nos que todos estes elementos não são nem originais, nem específicos desta obra, devendo ser lidos e interpretados à luz da estética Barroca, por um lado, à luz da história de geneologia literária, nomeadamente o aparecimento do romance epistolar, por outro lado, e, finalmente, à luz de uma retórica do amor, bem tradicional na lírica portuguesa e na novelística sentimental.

Note-se, aliás, a propósito do mito do natural epistolar, a existência de uma antinomia, bem patente no interior da prática epistolar, mediante a qual o natural depressa se transforma, sobretudo a partir do século XVII, num imperativo retórico do género. Conforme sublinha Brigitte Diaz, a escrita epistolar impõe-se simultânea e paradoxalmente como um campo de invenção linguística, em que o sujeito se assume na

nismo ou uma estratégia para que, ao menos, pareça o que não é (...) Trata-se de imitar uma outra forma de discurso, sabendo-se, à partida, que essa imitação é impossível - a naturalidade é assim mais fabricada do que a própria artificialidade que parece ser característica de formas mais elaboradas." (Almeida, 1988: 150).

6 "Grâce à une métaphore passée dans l'usage, elle [la lettre] est le «discours des absents». (...) Elle donne aux épistoliers qui s'extasient sur les miracles de la poste une ubiquité de papier. Mas cet émerveillement repose au fond sur une plante étouffée. L'absence est toujours à l'origine d'une correspondance." (Haroche-Bouzinac, $1995: 70)$. 
sua capacidade de individuação, e um campo em que os discursos são clonados de lugares comuns, de clichés e de fórmulas altamente codificadas (Diaz, 2002: 16).

Deste modo, a escrita da naturalidade depressa adquire uma dimensão prescritiva e imposta, a ponto de levar alguns escritores oitocentistas a encararem a carta com desconfiança, como um "género prostituído" a lugares comuns. Até a escrita modelar de Mme. de Sevigné, que tanto agradou aos cultores do género por tudo o que representava de negligente e natural, rapidamente se tornou uma imposição a seguir e a imitar, por todos os que quisessem sobressair na arte de bem escrever cartas. A defesa da espontaneidade, da naturalidade e da informalidade foram, desde tempos ancestrais, traços definidores do estilo epistolar ${ }^{7}$, o que nos conduz a uma leitura da naturalidade epistolar como caraterística inalienável da vertente social e cultural da carta, bem patente na proliferação dos manuais epistolares ao longo dos séculos XVII, XVIII e XIX ${ }^{8}$. A adoção de códigos de civilidade epistolar e de convenções discursivas, prescritas nestes tratados, transforma as relações afetivas de âmbito privado em relações regradas pelo espaço público.

A carta é, de facto, um objeto social, configurado por um discurso circunstanciado, através do qual o sujeito enunciador se apresenta mediante uma construção discursiva específica, sobre o plano pessoal e social, ao destinatário, afirmando um conjunto de valores, crenças e atitudes que geralmente vão ao encontro das expectativas do outro.

Neste sentido, a escrita da carta é sempre uma espécie de mise-en-scène - a que Cécile Dauphin chama de "teatralização da escrita"

${ }^{7}$ Por exemplo, Lípsio, tal como Erasmo, considera o género epistolar como um género espontâneo, descontraído e apto a traduzir as oscilações do sujeito que escreve. Já no século XVII, com Voiture, a carta abre-se à vida social e mundana e passa a absorver as características naturais da conversa de salão; no século XVIII, com Du Batteux, o género é visto como um género oratório rebaixado "au simple entretien" e, por isso, capaz de ser o espelho dos sentimentos (Almeida, 1988).

${ }^{8}$ Os manuais epistolares começam a surgir na Europa no século XVI, coincidindo com um período de aumento da correspondência familiar - não só decorrente de um alargamento das fronteiras e das distâncias mas também da revitalização que o Humanismo deu a esta prática - e também um período de implantação da literacia. Quer isto dizer que os manuais proliferaram acompanhando o incremento da prática epistolar, em relação à qual se impunham como modelos a imitar, com propósitos marcadamente formativos e didáticos. 
(Dauphin, 1995: 193) - que segue normas muito concretas, mantendo uma relativa margem de liberdade e de imaginação, e que institui atores sociais que se mascaram para se mostrar, fingindo construir imagens sinceras de si mesmos, mas que, apesar de tudo, mais não são do que reflexos e representações destinados ao teatro social e mundano. Nesta perspetiva, a troca epistolar é um intercâmbio extremamente ritualizado, que envolve um conjunto de regras de apresentação dos sujeitos, orientando o tipo de relação social que estabelecem e o grau de intimidade e de proximidade. O discurso epistolar é, assim, um discurso sempre contextualizado, dirigido e com uma importante dimensão social. Muito ligado a este mito da espontaneidade epistolar encontra-se também o motivo da sua feminilidade, pelo qual só a mulher tem a capacidade em exprimir, de forma verídica e natural, a sua subjetividade.

Desde a publicação das cartas da religiosa portuguesa, no fim do século XVII, que a carta é entendida como medium apropriado e adequado à expressão espontânea da intimidade e da paixão. Contudo, sublinhe-se que, tal como sucede com outras criações literárias da época, a negligência e a impulsividade das cartas de Mariana são efeitos textuais, mais pensados e refletidos do que à primeira vista possa parecer. Eles são o resultado de um conjunto de topoi da literatura sentimental, provenientes de Ovídio, das suas famosas Heroides, que se prolongam na lírica medieval e na novela sentimental quinhentista. Todos os autores que se interessam pelo estudo da forma epistolar, sobretudo da sua inserção na narrativa do romance epistolar, são unânimes em referir esta obra de Ovídio como uma referência incontornável da pré-história do género. Linda Kauffman, na obra Discourses of Desire, em que analisa sete narrativas epistolares, desde a Idade Média até ao século XX, reserva um capítulo introdutório às Heróides de Ovídio, considerando-as o locus classicus do discurso epistolar amoroso. Segundo a autora, Ovídio foi o primeiro a conceber as grandes possibilidades da forma epistolar, desenvolvendo um género com dinâmica dialógica e enfatizando o discurso das heroínas:

Discourses of desire are part of a tradition that is older even than Ovid, yet each discourse is just such a sustained critique. The Ovidian rhetorical ideal challenges the concepts of unity, fixidity, and consistency; instead, it celebrates the fluid, the multiple, the capricious. Rather than seeing illusion as veiling a central reality or a fixed truth, Ovid values 
illusion for its own sake and recognizes how large a role artifice plays in arousing desire (Kauffman, 1986: 21).

\section{A génese do romance epistolar}

Uma abordagem às Lettres Portugaises e às suas diferentes formas de integração no campo da Literatura não pode dispensar a questão da absorção da carta por um subgénero narrativo - o romance epistolar ${ }^{9}$ - em voga na Europa desde o século XVII, atingindo um período de maturidade e esplendor no decurso da centúria de setecentos, época que se revela muito fértil no que à epistolaridade diz respeito. Grande parte dessa riqueza advém precisamente do enorme sucesso que, tanto em Inglaterra, como em França, tiveram os romances epistolares, intimamente ligados à sociabilidade do século XVIII. Produto de uma nova relação entre público e privado, a esfera pública burguesa, no sentido habermasiano do termo, compaginou-se com a transformação do sistema literário, quer em termos de reorganização do campo institucional da literatura, em que surgem novos espaços sociodiscursivos urbanos, como os cafés, os teatros e os salões, quer em termos genológicos, assistindo-se ao aparecimento de novos géneros como resposta a novos anseios de um público também ele renovado e diferente.

Assim, o aparecimento de um novo subgénero literário como o romance epistolar, simbolicamente marcado pela publicação de Pamela do inglês Richardson, em 1740, bem como a valorização de géneros como o diário ou a carta, são sintomas de uma profunda alteração dos hábitos de leitura do público burguês e de uma profícua fusão entre público e privado, responsável, afinal, pela construção do espaço público setecentista ${ }^{10}$.

${ }^{9}$ Seguimos a definição de romance epistolar proposta por Robert-Adam Day que o entende como qualquer narrativa em prosa, longa ou curta, largamente ou integralmente imaginária na qual as cartas, parcial ou inteiramente ficcionais, são utilizadas como veículo de narração ou ocupam um importante papel no desenvolvimento da história (Day apud Versini, 1998: 10).

${ }^{10}$ Para Habermas, "las cartas ajenas no solo se prestan y transcribem; muchos intercambios epistolares están ya de antemano, como muestran en Alemania los ejemplos de Gellert, Gleim y Goethe, previstos para la imprenta. (...) Así se explica a partir de la subjetividad (...) de los intercambios epistolares y de los 
Contudo, algumas décadas antes do aparecimento de Pamela, é publicada em 1669 em França a obra Lettres Portugaises traduites en françois, de autoria desconhecida mas editadas por Claude Barbin, um célebre impressor parisiense. Embora a maioria da crítica não dedique esta perspetiva genológica às Lettres Portugaises, enfatizando outras questões já enunciadas, acreditamos que esta obra é, de facto, uma obra precursora do subgénero, como iremos demonstrar. Desde finais do século XVII até ao final do século XVIII, o romance epistolar constitui um caso espantoso de sucesso, conquistando e fidelizando um público leitor que ia alimentando a edição de obras do género.

Subgénero paradoxal e multifacetado, resultante de um conjunto muito diversificado de tradições - que vão desde os manuais epistolares e secretários, que começam a aparecer no século XVI, afirmando-se como códigos formais e práticos de escrita epistolar, até à poesia amorosa de influência petrarquista, passando pelas Heróides de Ovídio ${ }^{11}$, pelo romance medieval de Abelardo e Heloísa, pela novela sentimental espanhola, ou pelas recolhas e compilações de cartas de vocação pedagógica - o romance epistolar potencia a ambiguidade e a indefinição da forma epistolar que absorve. Assistimos, assim, a uma génese em muitos aspetos paradoxal que alia o lirismo sentimental ao utilitarismo, a naturalidade e autenticidade ao formalismo codificado, a ficção à realidade (Versini, 1998: 9).

Esta génese paradoxal e a tessitura de textos e de tradições que a conformam não são de todo estranhas às contradições da sociedade que conduziu este subgénero ao seu apogeu. Como qualquer outro, o subgénero do romance epistolar está intimamente ligado às especificidades socioculturais de uma época. Aparece como o reflexo de um período em que as duas grandes formas de sociabilidade eram a conversação e a carta, entendida esta como uma conversa por escrito; uma sociedade que renega a ficção, privilegiando a autenticidade, reforçada como já se disse pelo romance epistolar, projetando o natural como valor estético

diarios íntimos el origen del género típico y de la própria disposición literária de ese siglo: la novela burguesa, la descripción psicológica en forma autobiográfica." (Habermas, 2002: 86).

${ }^{11}$ Todos os autores que se interessam pelo estudo da forma epistolar, sobretudo da sua inserção na narrativa do romance epistolar, são unânimes em referir esta obra de Ovídio como uma referência incontornável da pré-história do género. 
mas, simultaneamente, uma sociedade extremamente codificada e normativa, sobretudo relativamente às regras de convivência e mobilidade sociais.

O sucesso deste subgénero ficou a dever-se, sobretudo, a três caraterísticas que absorve da epistolaridade que o estrutura - a autenticidade, a feminilidade e a privacidade (que gera a enunciação da subjetividade) - que o tornam mais vivo e factual, construído à imagem da vida real e, por isso, tocando intimamente o leitor que, por intermédio das cartas, acedia diretamente à interioridade das personagens e das heroínas, sem a mediação do narrador (Beugnot, 1978: 947) .

A autenticidade, decorrente, em parte, do facto de a carta ficcional assimilar algumas características da carta real ${ }^{12}$, nomeadamente $o$ recurso à linguagem corrente e familiar das cartas privadas, era uma característica muito cara ao leitor do século XVIII, época que geria mal o inverosímil, a ficção e o romanesco (Versini, 1998: 50). São diversificadas as estratégias de autentificação e de veridicção do romance epistolar, entre elas, o recurso a uma estética do pormenor favorecida pela relação que a forma epistolar estabelece com a escrita da vida privada, propícia ao relato do quotidiano; a utilização de discursos colonizados por práticas discursivas correntes, sobretudo pelo tom conversacional e irrefletido da fala quotidiana; finalmente, a referência, normalmente no espaço paratextual do prefácio ${ }^{13}$, ao autor / compilador / editor que, tendo tido acesso às cartas, as organiza e publica, mascarando assim o ato de criação literária, necessariamente fingida, das cartas. De facto, o romance epistolar, ao contrário de outros subgéneros contíguos, como

${ }^{12}$ Segundo Susan Wright, a ficção epistolar do final do século XVII e do século XVIII, sobretudo a ficção amorosa, tem muitas similitudes com a epistolaridade real: "Although aparently perceived as simple projection of the real love-letter, the ficcional love-letter is different from the authentic intimate letters (...) The source of the apparent similarity between real letters and fictional letters seems to be in the marriage of the private language of intimate letters with the linguistic conventions of the day which govern prose writing." (Wright, 1989: 556-557).

${ }^{13}$ Janet Altman, referindo-se à principal diferença entre as cartas reais e as ficcionais, diz o seguinte : "In fictional letters, where there is no historical "contexte vécu" as in a real correspondence, the illusion that something is going on between the letters or preceding the letters must be created without having the characters tell each other things they already know; this is usually accomplished by editorial footnotes, (...)" (Altman, 1982: 120). 
o diário, as memórias ou as confissões, responde a uma "exigência anti-romanesca", esbatendo as fronteiras entre ficção e real.

Deste modo, o romance epistolar assegurava um pacto de leitura diferente do de outro tipo de ficção: o leitor, mesmo sabendo estar a ler ficção, não o sentia enquanto tal, projetando o romance para a esfera de um conjunto de géneros autênticos. Traçando o percurso da leitura nos séculos XVI e XVII, Roger Duchêne defende que se verifica uma evolução no tipo de leitor e sobretudo nas expectativas de leitura: o leitor doutrinado e conhecedor, capaz de admirar as belezas dos grandes mestres, é substituído, gradualmente na viragem da centúria de quinhentos para a de seiscentos, pelo "leitor-consumidor" que encara as cartas como um prolongamento da vida social e que procura encontrar nelas uma "mise-en-scène" de experiências de vida, um texto autobiográfico onde o seu autor deixa marcas vívidas da sua vida e da sua personalidade. Esta evolução, que fez com que as coletâneas de cartas publicadas integrassem e explorassem assuntos do foro privado, mostra bem como a sinceridade e a autenticidade atingiram o patamar dos valores estéticos (Duchêne, 1978: 988). Na nossa opinião, esta alteração da leitura e a deslocação do ponto de interesse da leitura epistolar pode, em parte, explicar o tipo de leitor do romance epistolar setecentista: como um voyeur, o leitor absorve a ficção, como se de cartas reais se tratasse e, através delas, acede ao mundo interior, íntimo e privado das personagens, aderindo a um jogo perverso entre real e ficção.

$\mathrm{O}$ facto de a maioria das personagens principais serem mulheres e também porque boa parte do seu público leitor era feminino, o certo é que este subgénero está, tal como a escrita epistolar, intimamente ligado ao mito da epistolaridade feminina. Laurent Versini atribui esta ligação ao facto de as mulheres serem vistas, na sociedade da época, como seres mais propensos à sensibilidade do que à reflexão: menos racionais, por natureza e sobretudo pela instrução desleixada, as mulheres optam por um estilo espontâneo não se deixando influenciar tanto pela retórica (Versini, $1998: 59$ ).

À semelhança do que sucede com a mulher na escrita epistolar, também as heroínas do romance epistolar encaravam a escrita como uma forma de afirmação da sua identidade, um modo de acederem a uma tribuna não silenciada, de darem voz a sentimentos, pensamentos e emoções. Esta relação entre género e o romance epistolar liga-se também à autenticidade, naturalidade e negligência veiculadas pelo 
subgénero e inscritas na forma epistolar. A mulher aparece como o ser capaz de produzir discursos naturais, aparentemente desordenados e caóticos porque obedecendo à lei das paixões e do sentimento; a autenticidade da sua escrita, decorrente do menor índice de conhecimento de códigos, regras e sistemas, imprime ao romance epistolar a feição de vida vivida, de vida real que tanto agradava ao leitor do século XVIII.

Esta identificação ficou, em parte, a dever-se ao chamado "fenómeno Sévigné”: Mme. de Sévigné foi, de facto, como já explicitámos, a grande responsável pela projeção do epistolar como veículo do sentimento, da naturalidade, da verdade e da feminilidade. A carta surge, assim, intimamente associada a um universo de uma feminilidade supérflua, esvaziada de conteúdo, mas rica nos atributos de ligeireza, naturalidade e sentimentalidade, intuição e sinceridade.

$\mathrm{Na}$ verdade, a partir da publicação das cartas desta epistológrafa, assiste-se a três fenómenos interessantes, no âmbito das práticas epistolares: por um lado, a escrita de cartas é liberalizada, tornando-se acessível a todos aqueles que soubessem escrever, mesmo não pertencendo ao mundo dos literatos ou autores; por outro lado, e decorrente deste, a carta começa progressivamente a transpor as fronteiras do mundo da literatura, instituindo-se cada vez mais como uma prática eminentemente informativa; finalmente, a ideia de que o epistolar intimista é um domínio privilegiadamente feminino, reservado às mulheres e facilmente moldável às suas sensibilidade e superficialidade, recolhe também muitos consensos.

\section{As Cartas Portuguesas: escrita epistolar como processo transgressor}

Embora haja uma corrente da crítica que defende a veracidade da história da Soror Mariana, baseada inclusive em pesquisa documental, entendemos relegar essa questão para segundo plano, tal como declarámos no início. Independentemente da existência empírica da figura e da veracidade ou não destas cartas, entendemos que, a partir do momento em que são coligidas, ordenadas e publicadas por um editor, elas adquirem uma dimensão orgânica que escapa à lógica de julgamento referencial. Segundo Charles Porter, o papel de um editor de cartas vai muito 
mais além do que a simples recolha, organização e publicação, pois tais atividades interferem no estatuto literário dos textos ${ }^{14}$ :

Even if the editors think they are only trying to assure the reader's maximal comprehension, it is clear that they do more. Since with the editors' help we know at least parts of the future unknown to both the author and the addressee of the letters that have come down to us, letters in a series, all the more when they involve persons otherwise known, necessarily become parts of what in narrative and drama would be called plot (Porter, 1986: 14).

Quer isto dizer, portanto, que esta obra deve ser lida inevitavelmente enquanto tal, isto é, como obra literária, com todas as implicações que esta integração na esfera do literário transporta. Por tudo o que já dissemos até este momento, parece-nos importante clarificar o modo como entendemos as Lettres Portugaises: a tese que aqui defendemos é a de que se trata de um romance epistolar, deficitário quanto ao feedback comunicacional, em que um sujeito discursivo monta uma ficção narrativa renunciando a um elemento primordial da narrativa: a trama diegética. Ou seja, as cinco cartas que compõem a obra são peças de uma história cujos eventos foram substituídos por linguagem, por palavras e pelos efeitos desse mesmo discurso ${ }^{15}$. Através delas, Mariana, o eu epistolar, consegue uma afirmação e uma reconstrução de identidade, previamente destruída pelo trauma de uma separação amorosa. O destinatário epistolar é apenas um motivo, não assumindo as tradicionais funções de um destinatário na epistolaridade passional. Trata-se de

${ }^{14}$ No mesmo sentido vão as palavras de Janet Altman que entende que o ato de publicação de correspondências é decisivo na sua institucionalização como literatura: "What I shall be tracing is the way in wich published correspondences, whenever they address their paradoxical function of preserving the ephemeral, institutionalize themselves as literature or as literary documents and in so doing project or reinforce certain images of the 'Republic of Letters' at given moments in history." (Altman, 1986: 18).

${ }^{15}$ Segundo Jean Rousset esta é, na verdade, um topos da narrativa epistolar: "Il semble qu'avec l'avènement de la forme épistolaire, le romancier pour la première fois dans l'histoire du roman, renonce au récit (...) Ici, l'événement ce sont les paroles mêmes et l'effet à produire au moyen de ces paroles (...) » (Rousset, 1995: 74). 
uma narrativa centrada no sujeito, um sujeito que experiencia, de forma vívida, as etapas de um processo passional.

Como sublinhámos inicialmente, somos da opinião que grande parte do sucesso desta obra passa pelo jogo com a verosimilhança romanesca, propiciado pela epistolaridade, em que a ficção surge mascarada de realidade. A fronteira entre ficção e realidade é matizada, como, aliás, sucedia no subgénero do romance epistolar. $\mathrm{O}$ primeiro indício deste facto é o prefácio do editor que acompanha a primeira edição da obra, pois é ele o elemento paratextual fundamental que lança os protocolos de leitura do texto: o editor encontra, à custa de muito esforço, a cópia de cinco cartas portuguesas traduzidas, desconhece a identidade do autor epistolar, bem como do destinatário, mas julga importante trazê-las a público, a fim de as preservar de manipulações indevidas. Ou seja, este editor assume a responsabilidade da publicitação de um conjunto de cartas privadas, mascarando o ato de criação ficcional que terá presidido à sua construção. A partir daqui, estas cartas serão lidas e fruídas como peças que ilustram estados de alma, sensações, vivências e sujeitos empiricamente existentes. Esta verdade relativa do romance epistolar afeta-o tanto ao nível da história que conta, como ao nível do discurso que veicula. A história pode ser atingida pela dispersão e pela desordem, típicas de uma espontânea compilação de cartas, assim entendidas como documentos reais; o discurso das cartas deve ser tendencialmente negligente e desconexo, de forma a transmitir a ideia de fluxo verbal que acompanha as ondulações do sentir e o pulsar quotidiano das paixões.

Trata-se de uma estratégia de veridicção ${ }^{16}$ continuada ao longo das cartas: para além dos inúmeros referentes a locais e tempos históricos

${ }^{16}$ Utilizamos a expressão "veridicção" no sentido semiótico que lhe é atribuída por Greimas e Courtès, segundo os quais, a transmissão da verdade depende unicamente de estratégias epistémicas utilizadas na cadeia comunicacional, tanto ao nível da instância enunciadora como ao nível da receção: "un creer verdad debe instalarse en los dos extremos del canal de la communicación y a este equilíbrio más o menos estable, a este entendimiento tácito de dos cómplices más o menos conscientes, lo denominamos contrato de veridicción o contrato enunciativo." (Greimas e Courtès, 1982: 432-434). E, mais à frente, acrescentam: "El enunciador ya no es considerado productor de discursos verdaderos, sino de discursos que producen un efecto de sentido de "verdad": desde este punto de vista, la producción de la verdad corresponde al ejercicio de un hacer cognoscitivo particular, el hacer 
determinados que, inclusive, terão propiciado toda uma investigação histórica em torno da existência de uma freira Mariana Alcoforado, as inúmeras alusões ao ato de escrita e aos intermediários portadores das missivas contribuem indiscutivelmente para essa estratégia de verosimilhança.

Este aspeto é, em nossa opinião, crucial para entendermos a originalidade deste romance epistolar, na medida em que se percebe, à medida que a relação epistolar evolui, a centralidade ocupada pelo ato de escrita do sujeito Mariana. A dado momento, na penúltima carta, lê-se o seguinte:

Vou recomeçar, e o oficial partirá. Que importa que ele parta? Eu escrevo mais para mim do que para ti, e aquilo que procuro é consolarme. Por isso vais-te assustar com a extensão da minha carta e nem a chegarás a ler... (Alcoforado, 2004: 75).

Esta questão assume contornos especiais, sendo este um romance epistolar, género em que o leitor adquire geralmente uma especial acuidade. A caraterística distintiva da carta, enquanto género discursivo, é precisamente a presença do destinatário: uma carta existe sempre em função de alguém a quem é dirigida, daí que Janet Altman considere a forma epistolar a única que tem aptidões para retratar a experiência de leitura. Por isso, a narrativa epistolar transforma o ato de leitura num evento diegético, narrativizando a leitura e integrando-a na ficção (Altman, 1982). No caso das Lettres Portugaises, é o ato de produção do discurso o elemento diegético fundamental, o que secundariza de certa forma o destinatário eleito. Será através do discurso que Mariana enceta um processo catártico de autoanálise, que lhe permitirá trilhar um processo de racionalização. Uma leitura comparada das primeira e última cartas torna bem evidente essa evolução: se, na primeira carta, as antinomias, as contradições e a hiperbolização da perturbação são marcas evidentes no discurso, na última carta, há claramente uma exercício de contenção e de refreamento das paixões, aliás, enunciado pela própria Mariana logo na abertura:

parecer verdad, que puede ser denominado, sin ningún matiz peyorativo, hacer persuasivo." (Greimas, 1982: 433). 
Escrevo-lhe pela última vez, e espero fazer-lhe saber, pela diferença dos termos e do tom desta carta, que, finalmente, me persuadiu de que já não me amava e que, portanto, também eu devo deixar de o amar (Alcoforado, 2004: 81).

A alteração no modo de tratamento do destinatário - da segunda pessoa das outras cartas, marca de intimidade, passa a usar a terceira pessoa, marca de distanciamento -, a construção de períodos muito mais longos e sintaticamente mais complexos e a dimensão argumentativa são marcas discursivas que denunciam o culminar de um processo de consciencialização, de autognose, só possível pela escrita. Lembremos aqui as palavras de Barthes, no seu célebre Fragmentos de um discurso amoroso:

Saber que não se escreve para o outro, saber que isto que vou escrever não me fará nunca ser amado por quem amo, saber que a escrita nada compensa, nada sublima, que está precisamente aí onde tu não estás -éo começo da escrita (Barthes, 2010: 128).

No entanto, o destinatário é uma peça importante em todo este caminho e obliterá-lo seria negar a dimensão epistolar desta obra. Será a relação com esse outro ausente, figura epistolar, que permite ao sujeito não só ter vivenciado as contradições do amor, como também superá-las, através de um processo de autoconhecimento. $\mathrm{O}$ epistolar promove a ausência e a distância, sendo precisamente a ausência do outro a alavanca do gesto epistolar, pois o epistológrafo substitui o destinatário por uma representação. Nesta ótica, compreende-se o recurso à metáfora fúnebre ${ }^{17}$, frequentemente ligada ao gesto epistolar: a carta como prova da morte e do desaparecimento do destinatário, substituído, através da escrita - por definição e essência, testamentária - por imagens e representações. A carta é muito mais um princípio de distanciamento do que de aproximação: esta distância e a solidão da escrita epistolar,

17 “D'où aussi la profonde affinité de l'épistolaire avec le discours littéraire proprement dit, que l'on peut définir minimalement comme n'étant jamais adressé à un autre en particulier ; comme se produisant toujours sur fond de disparition ou de destruction de l'autre. (...) Les correspondances préparent au deuil de l'autre ; c'est ce qui leur donne du même coup, très souvent, une valeur d'initiation à l'écriture proprement dite." (Kaufmann, 1990 : 148). 
a sua não-destinação, são marcas que fazem do epistolar e do literário dois tipos de escrita convergentes (Kaufmann, 1986: 391).

Afinal, a mesma solidão presente necessariamente em todo o amor, entendendo-se este como um processo de mudança radical, de afirmação do sujeito, de reconstrução da identidade e de transgressão. Como Barthes refere, contrariando um avisado conselho de Mme de Merteuil, "a carta, para o apaixonado, não tem qualquer valor tático: é puramente expressiva (...)" (Barthes, 2010: 58).

\section{Bibliografia}

Almeida, M. T. S, (1988). Para uma estilística da carta - La Nouvelle Héloïse, Tese de Doutoramento, Universidade Nova de Lisboa.

DAuPhin, C. et alii (1995). Ces bonnes lettres. Une correspondance familiale au XIX ${ }^{\text {ème }}$ siècle. Paris : Albin Michel.

DECKER, W. M., (1998). Epistolary practices. Letter writing in America before telecommunications, The University of North Carolina Press.

Diaz, J.L. (1998). «Il est interdit de penser par lettre», Melançon, B., (dir.), Penser par lettres. Actes du colloque d'Azay-le-Ferron (mai 1997). Québec: Fides, pp. 13-35.

DiAz, J.L., (1998). «La féminité de la lettre dans l'imaginaire critique au XIX ${ }^{\text {ème }}$ siècle», Planté, C., (org.), L'épistolaire, un genre féminin? Paris : Honoré Champion Editeur, pp.153-177.

DiAz, B . (2002). L'épistolaire ou la pensée nomade. Paris: P.U.F.

Foucault, M. (1995). «A escrita de si». In: O que é um autor?, 2. ${ }^{a}$ ed., Lisboa: Vega, pp. 129-160.

Greimas, A. J. e Courtès, J., (1982). Semiótica. Diccionario razonado de la teoria del lenguaje. Madrid: Editorial Gredos.

Habermas, J., (2002). Historia y crítica de la opinión pública. La transformación estructural de la vida pública, Madrid, Ediciones G. Gili.

Kauffman, L. (1986). Discourses of desire. Gender, genre and epistolary fictions. Ithaca and London: Cornell University Press.

Kaufmann, V., (1986), «Relations épistolaires. De Flaubert à Artaud», Poétique, n. $^{\circ} 68$, Nov., pp. 387-404.

Klobucka, A. (2006). Mariana Alcoforado. Formação de um mito cultural. Lisboa: INCM. 
Menéndez Y Pelayo, M., (1961). Orígenes de la novela, Tomo II, 2. a ed. Madrid: C.S.I.C.

Moisés, M. (2002). A literatura portuguesa através dos textos. São Paulo: Cultrix.

PASK, K., (2004). «The bourgeois public sphere and the concept of literature», Www.findarticles.com

Paradinha, M. (2006). As cartas de Soror Mariana Alcoforado. Manipulação e identidade nacional. Casal de Cambra : Caleidoscópio.

Peixinho, A. T. (2011). A epistolaridade nos textos de imprensa de Eça de Queirós. Lisboa : FCG.

Planté, C. (org.), (1998). L'épistolaire, un genre féminin? Paris : Honoré Champion Editeur.

Porter, C. A., (1986), «Foreword». In: Yale French Studies, №71, Men / Women of Letters, pp. 1-14, Yale University Press http://links.jstor.org/sic i? sici=00440078\%281986\%290\%3A71\%3C1\%3AF\%3E2.0.CO\%3B2-S [consultado em maio de 2011]

Rousset, J. (1995). «Une forme littéraire : le roman par lettres», Forme et Signification, $14^{\mathrm{a}}$ ed., Paris : José Corti, pp. 65-103.

VERSINI, L., (1998). Le roman épistolaire, 2. a ed. Paris, P.U.F. 